\title{
IDENTIFICATION BY CAPILLARY GAS CHROMATOGRAPHY-MASS SPECTROMETRY OF ELEVEN NON-ECDYSTEROID STEROIDS IN THE HAEMOLYMPH OF LARVAE OF SARCOPHAGA BULLATA
}

\author{
D. De Clerck*, H. Diederik $\dagger$ and A. De LoOF* \\ *University of Leuven, Zoological Institute, Naamsestraat 59, B-3000 Leuven, Belgium and †University \\ of Utrecht, Zoological Laboratory, Section for Comparative Endocrinology, Padualaan 8, $3584 \mathrm{CH}$ \\ Utrecht, The Netherlands
}

(Received 15 April 1983; revised 10 August 1983)

\begin{abstract}
O-Pentafluorobenzyloxime (OPFB)-heptafluorobutyrylester (HFB) derivatives and OPFB- $O$-methyloxime (MO)-trimethylsilylether (TMS) derivatives of non-ecdysteroid steroids were prepared from haemolymph extracts of last instar larvae of the fleshfly Sarcophaga bullata. Using a negative ion chemical ionization capillary gas chromatography-mass spectrometry (NCI/GC-MS) technique the following steroids could be identified: progesterone, testosterone, $5 \alpha$-androstane$3 \beta, 17 \beta$-diol, $5 \beta$-androstane- $3 \alpha, 17 \beta$-diol, androst-5-ene- $3 \beta, 17 \beta$-diol, androstenedione, $5 \alpha$-dihydrotestosterone, 11-ketotestosterone, $11 \beta$-hydroxytestosterone, $17 \alpha$-hydroxyprogesterone, $17 \alpha, 20 \beta$-dihydroxyprogesterone. Although the technique is very sensitive, estrogens could not be detected. These results suggest an active metabolism of progesterone and testosterone.
\end{abstract}

Key Word Index: Non-ecdysteroids, insects, metabolism, insect hormones

\section{INTRODUCTION}

For a long time the endocrine system of insects was supposed to be much less complicated than that of vertebrates. The number of peptide and steroid hormones identified in insects is indeed much smaller than in vertebrates. However, in the same way as the introduction of recent immunological methods has caused an increase in peptide hormones identification, the refining of mass spectrometrical methods now allows the identification of low concentrations of steroids in small samples (Burlingame et al., 1982). In a previous paper (De Clerck et al., 1983) we have already described the identification of testosterone and progesterone in the haemolymph of Sarcophaga bullata larvae. In this paper we give further proof not only for the presence of these steroids, but also of nine other steroids which are probably precursors and metabolites of progesterone and testosterone.

\section{MATERIALS AND METHODS}

\section{Steroid nomenclature}

Progesterone $=$ Pregn-4-ene-3,20-dione; $\quad 17 \alpha-$ Hydroxy progesterone $=$ Pregn-4-ene-17 $\alpha$-ol-3,20-dione; $17 \alpha, 20 \beta$ Dihydroxyprogesterone $=$ Pregn-4-ene-17 $\alpha, 20 \beta$-diole-3one; Testosterone $=$ Androst-4-ene-17 $\beta$-ol-3-one; Androstenedione $=$ Androst-4-ene-3,17-dione; Dehydroepiandrosterone $=$ Androst-5-ene-3 $\beta$-ol-17-one; 11-Ketotestosterone $=$ Androst-4-ene-17 $\beta$-ol-3,11-dione; $11 \beta$ Hydroxytestosterone $=$ Androst-4-ene-11 $\beta, 17 \beta$-diole-3one; $5 \alpha$-Dihydrotestosterone $=5 \alpha$-Androstane- $17 \beta$-ol3-one; Androstenediole $=$ Androst-5-ene-3 $\beta, 17 \beta$-diole; $11 \beta$-Hydroxyetiocholanolone $=5 \beta$-Androstan $-3 \alpha, 11 \beta$ diole-17-one.

\section{Animals}

S. bullata were cultured as described elsewhere (Huybrechts and De Loof, 1981). Haemolymph from unsexed last instar larvae which had left the food and which had emptied their gut was used. By insertion of the tip of a capillary into the body cavity, approx. $50 \mu \mathrm{l}$ haemolymph was collected from each larva, immediately cooled on ice, centrifuged at $3000 \mathrm{~g}$ for $5 \mathrm{~min}$ at $4^{\circ} \mathrm{C}$ to remove tissue and cells and then stored at $-20^{\circ} \mathrm{C}$ until use. A volume of $3.0 \mathrm{ml}$ haemolymph, which had been stored for a maximum period of one month, was used in the analysis.

Negative ion chemical ionization gas chromatography-mass spectrometry ( $N C I / G C-M S$ )

Analyses were done with a HP 5985B/GC-MS-DS instrument. The procedure for extraction, ion-pair extraction inclusive and capillary gas chromatographic separation are outlined by Diederik and Lambert (1982). The derivatization reaction of the keto-steroids to the $O$ pentafluorobenzyloxime (OPFB) derivatives and of the hydroxyl-functions to the hepatfluorobutyrylesters (HFB) have been described (De Clerck et al., 1983). For some steroids the hydroxyl-functions were converted to the trimethylsilylether derivatives as described further on. Initially, derivatives were prepared to improve the thermal stability of the polar molecules and to reduce their interaction with active centres in the chromatographic column and thus improve peak shape and separation characteristics. However, derivatives have also been prepared to improve the resolution of complex steroid mixtures by selectively altering the retention time of a group of steroids with a 3-oxo-function so that after OPFB-oximation they occupy a relatively empty region of the chromatogram. Respectively the (mono or di)-ester-, the OPFB-ester- and finally the di-OPFB-oxime derivatized steroids will elute from the capillary column; an elution pattern which cannot be achieved after $O$-methyl-oxime-HFB derivatization. Therefore if the derivatization reaction could be made selective for 
the substance(s) of interest in the mixture and the reagent so designed that it could be used in conjunction with a selective detector for the determination, there exists the possibility for the development of analytical schemes for complex mixtures (Poole and Zlatkis, 1980). In some cases (e.g. androstenedione) it is useful to demonstrate the presence of at least two keto-functions in the steroid molecule. Therefore the 3-keto-function was converted to the OPFBoxime as described by Diederik and Lambert (1982) and by De Clerck et al. (1983), after which the keto-function at the $\mathrm{C}-17$ or $\mathrm{C}-20$ position was converted into its $O$-methyloxime (MO) by using the oxime-exchange-technique of Axelson (1978). After OPFB-oximation the sample was heated at $100^{\circ} \mathrm{C}$ for $1 \mathrm{hr}$ with $0.1 \mathrm{ml}$ of a $2 \%(\mathrm{v} / \mathrm{w})$ solution of methoxyamine hydrochloride in dry pyridine in order to introduce a methoxime at the $\mathrm{C}-17$ or $\mathrm{C}-20$ position. Excess pyridine was removed under nitrogen at $100^{\circ} \mathrm{C}$. After the addition of $0.1 \mathrm{ml}$ of $N$-trimethylsilylimidazole (TSIM) persilylation of the hydroxylfunctions was achieved in $1.5 \mathrm{hr}$ at $110^{\circ} \mathrm{C}$ (Leunissen and Thyssen, 1978; Horning et al., 1968). Purification of the OPFB-MO-OTMS-derivatives after removal under nitrogen at $80^{\circ} \mathrm{C}$ of the excess of TSIM was carried out by liquid/liquid-extraction as described earlier by Diederik and Lambert (1982).

The $O$-pentafluorobenzyloxime and the methoxime of the keto-function increase the molecular weight by 195 and 29 per keto-group respectively and the heptafluorobutyrylester and the $O$-trimethylsilylether increase the molecular weight by 196 and 72 respectively. These steroid derivatives possess high molecular weights. This increases the sensitivity and specificity since the background noise is much lower in the higher mass range (Gleispach et al., 1981). The electron capture negative ion chemical ionization mass spectrometric technique was chosen to record the spectra of these electrophylic substituted derivatives (Markey et al., 1978). This technique provides enhanced sample ion current and also a significantly reduced background noise. Furthermore, using this technique, there is a low probability that a sample ion at a particular $m / e$ ratio will be obscured by the presence of a fragment ion derived from a high molecular weight contaminant, unresolved from the sample by the GC conditions employed in the analysis (Hunt and Crow, 1978).

If the concentrations were high enough, the steroids in the haemolymph extract were identified by comparing the obtained normalized NCI mass spectra out of a total ion current with a scan window m/e of 400-1000 with the spectra of standards at the expected GC retention time under negative ion conditions using methane as a reagent gas. For the low concentration of steroids in the haemolymph extract multiple ion recording of preselected ions (selected ion monitoring, SIM-data) was used for reconstruction of mass fragmentograms to confirm the molecularor (M-HF)-anion of the steroid derivatives at their expected $\mathrm{GC}$ retention times.

\section{RESULTS}

\section{Identification of $5 \alpha$-androstane, $3 \beta, 17 \beta$-diole}

The di-heptafluorobutyryl derivative of standard $5 \alpha$-androstane- $3 \beta, 17 \beta$-diole $(5 \alpha$-androstane- $3 \beta, 17 \beta$ diole-di-HFB, mol. $w \mathrm{t}=684.3$ ) has a retention time of $9.55 \mathrm{~min}$. The characteristic fragment-ions are $m / e$ of $684.3(\mathrm{M}), m / e$ of $664.3(\mathrm{M}-\mathrm{HF})$ and $m / e$ of 644.4 $(\mathrm{M}-2 \times \mathrm{HF})($ Fig. 1A). The characteristic fragmentions of standard $5 \beta$-androstane- $3 \alpha, 17 \beta$-diole-diHFB (mol. wt $=684.3$ ) are also $m / e$ of $684.3(\mathrm{M})$, $m / e$ of 664 . 2 (M-HF) and $m / e$ of $644.2(\mathrm{M}-2 \times \mathrm{HF})$ but since the retention time of this steroid is $7.95 \mathrm{~min}$ (Fig. 1B), both compounds can be easily separated. The molecular anion or an (M-HF)-ion carries most of the sample current under these NCI conditions
(Hunt and Crow, 1978). The same three fragmentions could be detected in the haemolymph extract at retention time $9.60 \mathrm{~min}$ (Fig. $1 \mathrm{C}$ ) indicating the presence of $5 \alpha$-androstane- $3 \beta, 17 \beta$-diole-di-HFB. Additional evidence comes from the relative abundance ratio of the (M-HF)-ion isotopes, that is expected from the number of C-atoms present in $5 \alpha$-androstane- $3 \beta, 17 \beta$-diole-di-HFB (McLafferty, 1980 ). The deviation in isotopic ratio between standard and haemolymph extract of the $m / e$ of 665.3 and $m / e$ of 666.2 ions is not unusual because of the difference in the signal to noise ratio for these ions (Fig. 1A and 1C).

Evidence for the presence of $5 \beta$-androstane$3 \alpha, 17 \beta$-diole-di-HFB in the haemolymph extract could not be obtained from the reconstructed mass fragmentograms at the proper retention time of $7.95 \mathrm{~min}$ out of a total ion current, monitored with a scan window $m / e$ of $500-700$, because of the relatively low signal to noise ratio. We therefore tried selected ion monitoring (SIM)-analysis for the already mentioned characteristic fragment-ions of both $5 \alpha$-androstane- $3 \beta, 17 \beta$-diole-di-HFB and $5 \beta$-androstane- $3 \alpha, 17 \beta$-diole-di-HFB. A small peak for these ions was found at retention time $7.95 \mathrm{~min}$ ( $5 \beta$-androstane- $3 \alpha, 17 \beta$-diole-di-HFB) and a much larger peak at $9.55 \mathrm{~min}(5 \alpha$-androstane- $3 \beta, 17 \beta$-dioledi-HFB) (Fig. 3B).

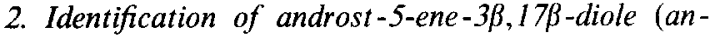 drostenediole)}

The typical fragment-ions of standard androstenediole-di-HFB (mol. $\mathrm{wt}=682.3$ ) are: $m / e$ of $662.2(\mathrm{M}-\mathrm{HF}$ ) and $m / e$ of 642.2 (M-2 $\times \mathrm{HF}$ ) (Fig. 2A). The retention time of this compound is $9.18 \mathrm{~min}$. In the haemolymph extract the same fragment-ions were also found at a retention time of $9.18 \mathrm{~min}$ (Fig. $2 \mathrm{~B}$ and $2 \mathrm{C}$ ). Selected ion monitoring analysis between 7 and $12 \mathrm{~min}$ showed that in the haemolymph extract the 662.2 fragment-ion occurs only once, namely at $9.18 \mathrm{~min}$, the typical retention time of androstenediole-di-HFB (Fig. 3B). The background corrected normalized mass spectrum of androstenediole-di-HFB is shown in Fig. $2 \mathrm{C}$, the evidence is that androst-5-ene- $3 \beta, 17 \beta$-diole is present in the haemolymph.

\section{Absence of estradiol (178)}

The discrimination between estradiol $(17 \beta)$ diHFB (mol. $w t=664.3$ ), $5 \beta$-androstane- $3 \alpha, 17 \beta$-dioledi-HFB and $5 \alpha$-androstane- $3 \beta, 17 \beta$-diole-di-HFB requires careful analysis of all data. The major problems are that all three compounds have a common fragment-ion, namely $m / e$ of 644.3 , that the retention time of estradiol $(17 \beta)$ di-HFB $(9.20 \mathrm{~min})$ is also close to that of $5 \alpha$-androstane- $3 \beta, 17 \beta$-diole-di-HFB $(9.55 \mathrm{~min})$ and finally that estrogens are also collected in the same tetramethylammoniumhydroxide (TMAOH) fraction as $5 \beta$ and $5 \alpha$-androstanediole as a result of the ion-pair extraction procedure (Diederik and Lambert, 1982). SIM analysis failed to provide evidence for the presence of estradiol(17 $\beta$ )-di-HFB for the following reasons.

If the fragment-ion $m / e$ of 644 should originate from estradiol(17 $\beta$ )-di-HFB as the (M-HF)-ion (Fig. $3 \mathrm{~A}$ and $\mathrm{B}$ ) with an abundance of 1494 area units, then 

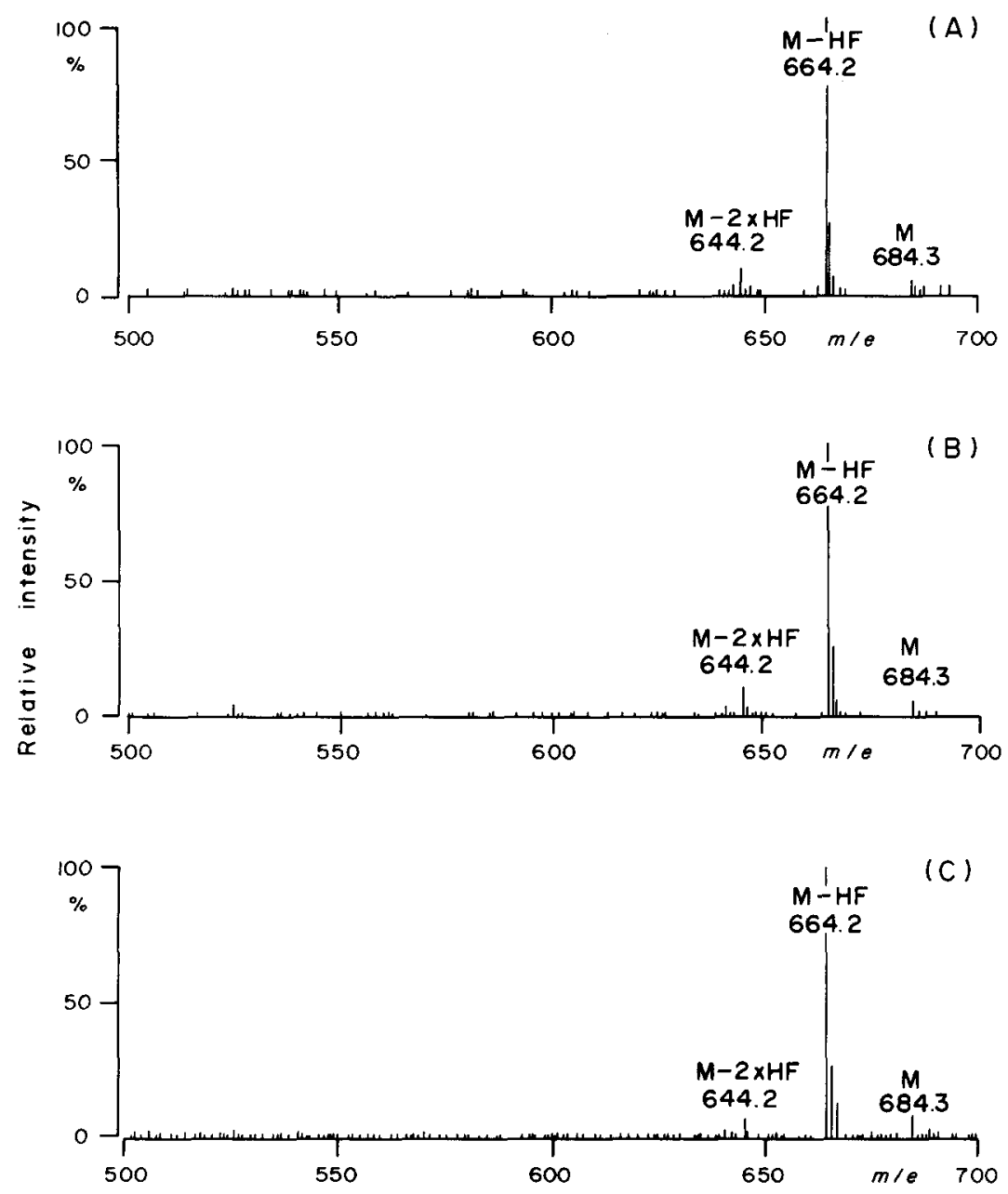

Fig. 1. Normalized $\mathrm{NCI} / \mathrm{CH}_{4}$ mass spectrum. (A) Of the standard $5 \alpha$-androstane- $3 \beta, 17 \beta$-diole-di-HFB (mol. $w t=684.3$ ) at retention time of $9.55 \mathrm{~min}$. Fragment-ions: $m / e 684 ; m / e 664 ; m / e$ 644. Isotopic ratio (M-HF)-ion: 100:28.3:5.1. (B) Of the standard $5 \beta$-androstane-3 $\alpha, 17 \beta$-diole-di-HFB $(\mathrm{mol} . \mathrm{wt}=684.3)$ at rention time of $7.95 \mathrm{~min}$. Fragment-ions: $\mathrm{m} / \mathrm{e}$ 684; $\mathrm{m} / \mathrm{e} 664 ; \mathrm{m} / \mathrm{e}$ 644. Isotopic ratio (M-HF)-ion: $100: 26.0: 5.0$. (C) Out of haemolymph from larvae of $S$. bullata at retention time 9.60 min. Fragment-ions: $m / e$ 684; $m / e$ 664; $m / e$ 644. Isotopic ratio (M-HF)-ion: 100:25.9:12.5.

the fragment-ion with $m / e$ of 427 should also be present at the same retention time (M-2 $\times$ HF-HFB). The mass fragmentogram of $m / e 427$ shows a peak which, on one hand is not intense enough, and on the other, has a slightly different retention time to that of the peak derived from the $m / e$ of 644 mass fragmentogram.

A reconstruction of the mass fragmentogram of mixtures of standards is represented in Fig. 3C in which the important ions of both estradiol $(17 \beta)$-di-HFB and $5 \alpha$-androstane- $3 \beta, 17 \beta$ diole-di-HFB were monitored. For the fragment-ion $m / e$ of 427 we find an abundance of $7769 \times 1.251$ (scale of the ordinate) $=9719$ and for the fragmention $m / e$ of $644,7303 \times 0.997=7281$. So the ratio of the two fragment-ions $427 / 644$ has an abundance ratio of about 1.33 in the SIM analysis, which is also the same for the relative abundance ratio of these two ions found in the mass spectrum $(427 / 644=100 / 72.8$; Fig. 3A).

\section{Identification of progesterone, testosterone and $5 \alpha$-dihydrotestosterone}

The NCI mass spectra of standard progesterone and testosterone and the corresponding compounds in the haemolymph of their OPFB-HFB derivatives, determined by monitoring the total ion current (scan window $m / e$ 400-1000), has already been described (De Clerck et al., 1983). In the present study, additional evidence is presented for the occurrence of both progesterone and testosterone in the haemolymph determined by selective ion monitoring (SIM) analysis of two different derivatives.

After OPFB-MO-OTMS derivatization of a standard mixture and of a haemolymph extract, the (M-HF)-ion of testosterone-OPFB-OTMS ( $m / e$ of 535.2) were found in the haemolymph extract (Fig. 4B) at a shifted retention time of 1 min longer compared to the standard mixture (Fig. 4A). Although the relative retention time of 
( A )
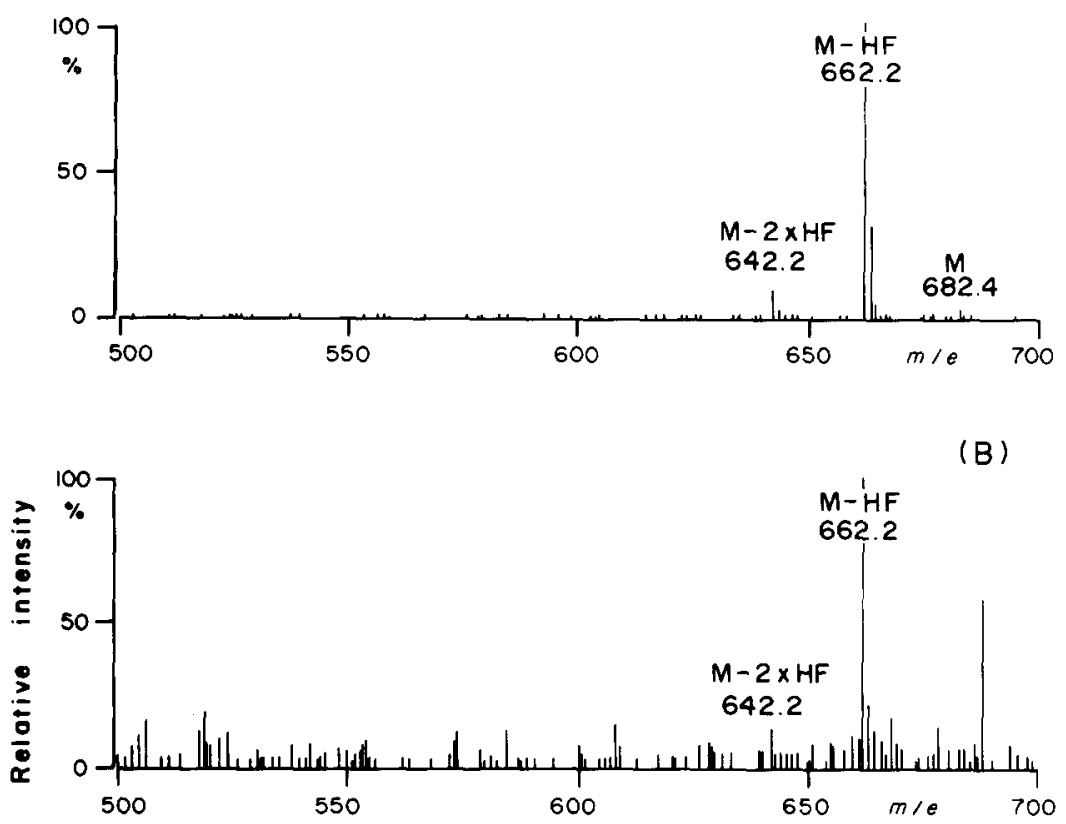

(c)

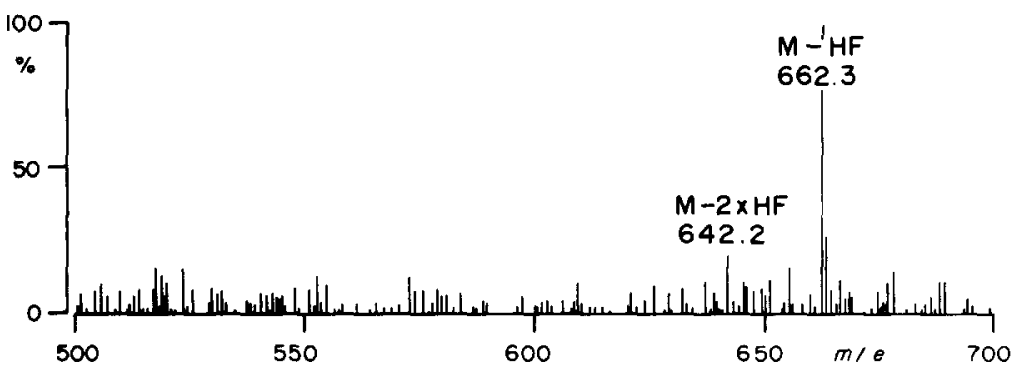

Fig. 2. Normalized $\mathrm{NCI} / \mathrm{CH}_{4}$ mass spectrum. (A) Of the standard androst-5-ene-3 $\beta, 17 \beta$-diole-di-HFB at retention time of $9.18 \mathrm{~min}$. Fragment-ions: $\mathrm{m} / \mathrm{e} 682 ; \mathrm{m} / \mathrm{e} 662 ; \mathrm{m} / \mathrm{e} 642$. Isotopic ratio (M-HF)-ion: $100: 31.3: 4.9$. (B) Out of haemolymph from larvae of $S$. bullata at retention time 9.18 min without background correction. Fragment ions: $m / e \quad 662 ; m / e$ 642. (C) Out of haemolymph from larvae of $S$. bullata at retention time $9.18 \mathrm{~min}$ after background correction. Fragment-ions: $m / e$ 662; $m / e 642$.

testosterone-OPFB-OTMS to the internal standard ( $11 \beta$-hydroxyetiocholanolone-OPFB-di-OTMS) is the same for the standard mixture as for the haemolymph extract, the reason for the increased retention time in the haemolymph extract will be described later. The (M-HF)-ion of progesterone-di-OPFB (anti) with $m / e$ of 684.1 were found in the haemolymph extract at the same retention time $(50.95 \mathrm{~min})$ as in the standard mixture. Since there is no (M-HF)-ion with $m / e$ of 535.2 present at retention time $29.30 \mathrm{~min}$ in the SIM analysis of the haemolymph extract (Fig. 4B), we must conclude that there is an absence of dehydroepiandrosterone in the haemolymph. This confirms our earlier results after OPFB-HFB derivatization of a haemolymph extract (De Clerck et al., 1983).

The SIM analysis of a haemolymph extract after OPFB-HFB derivatization proved the presence of the (M-HF)-ions of testosterone-OPFB-HFB ( $m / e$ of 659.3), the (M-HF)-ions of progesterone-OPFB $(m / e$ of 489.3$)$ and the (M-HF) ion of $5 \alpha$-dihydrotestosterone-OPFB-HFB ( $m / e$ of 661.3 ) though at an approx. 2 min longer retention time as the comparable standard derivative (Fig. 6A and B). This can be explained by the fact that in the capillary gas chromatography these steroid derivatives are immediately preceded by cholesterol-HFB present in the derivatized haemolymph extract. The latter has a well known retarding effect, due to thermal degradation of cholesterol-HFB, eliminating heptafluorobutyric acid during the gas chromatography (Francis et al., 1978).

This was confirmed by adding an internal standard, $11 \beta$-hydroxyetiocholanolone-OPFB-di-HFB, to the haemolymph extract which eluted in between cholesterol-HFB and all other steroid derivatives. This standard also has an increased retention time of about 2 min compared to its retention time in the 


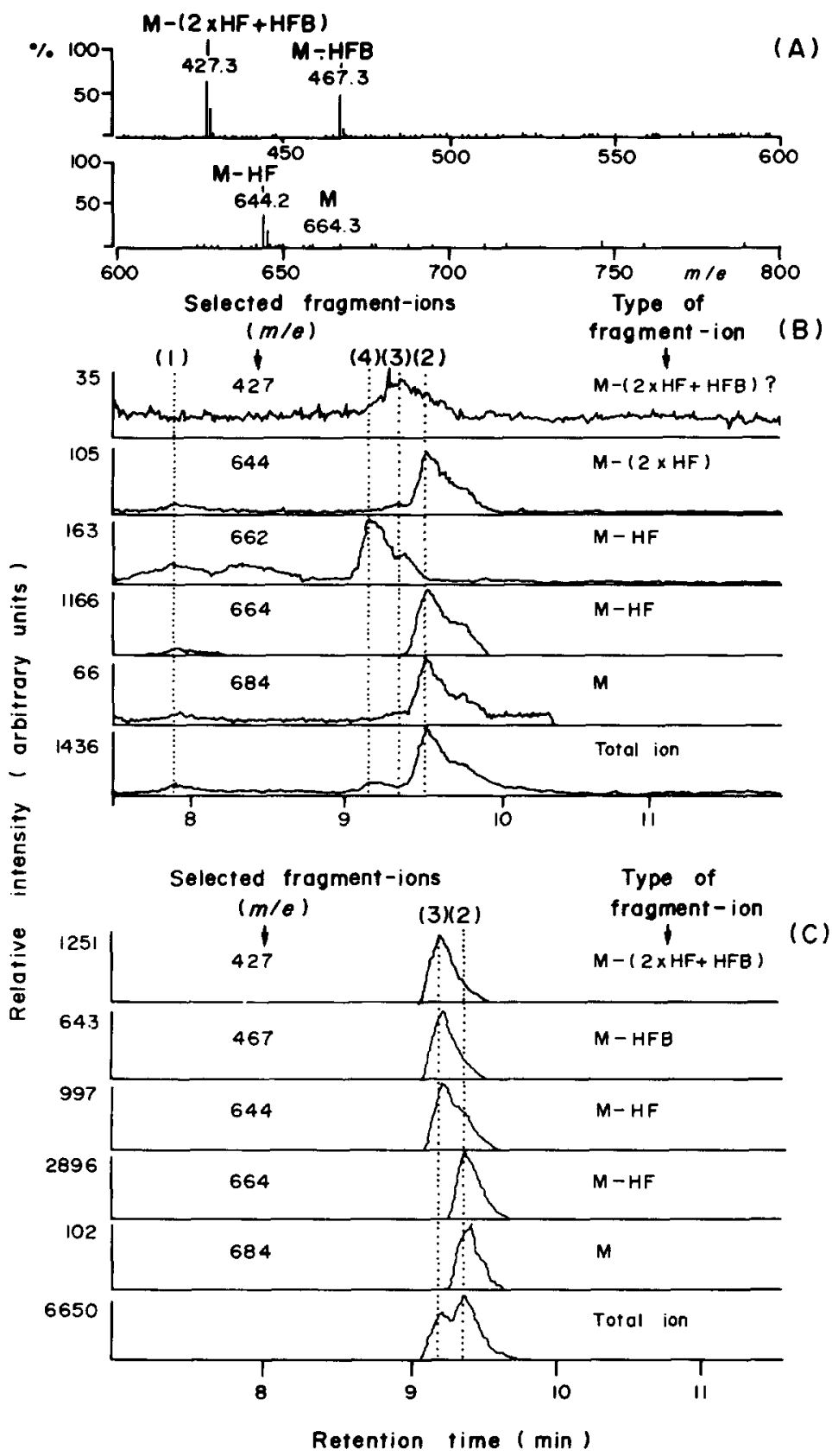

Fig. 3. (A) Normalized $\mathrm{NCl} / \mathrm{CH}_{4}$ mass spectrum of standard estradiol (17 $\beta$ )-di-HFB at retention time of $9.20 \mathrm{~min}$. Fragment ions: $m / e$ 644; $m / e$ 427; $m / e$ 467. Isotopic ratio (M-HF)-ion: 72.8:21.0:3.9. Isotopic ratio base peak: 100:33.0:5.9. (B) A reconstruction of the mass fragmentograms out of haemolymph from larvae of $S$. bullata during 7 to $12 \mathrm{~min}$ of five characteristic fragment ions $(\mathrm{m} / \mathrm{e} 684 ; \mathrm{m} / \mathrm{e} 664 ; \mathrm{m} / \mathrm{e} 644$ with peak abundance of 1494 area units) for (1) $5 \beta$-androstane- $3 \alpha, 17 \beta$-diole-di-HFB at retention time of $7.95 \mathrm{~min}$ and for (2) $5 \alpha$-androstane-3 $3,17 \beta$-diole-di-HFB at retention time of $9.60 \mathrm{~min}(\mathrm{~m} / \mathrm{e} 644 ; \mathrm{m} / \mathrm{e}$ 427 with peak abundance of 415 area units) for (3) estradiol (17B)-di-HFB at the approximately expected retention time of $9.30 \mathrm{~min}$ and $(\mathrm{m} / \mathrm{e} 662)$ for (4) androst-5-ene-3 $\beta, 17 \beta$ diole-di-HFB at retention time of $9.20 \mathrm{~min}$ out of a selected ion monitoring (SIM) analysis of these ions under $\mathrm{NCI} / \mathrm{CH}_{4}$ conditions. (C) A reconstruction of the mass fragmentograms of the characteristic ions of standard (3) estradiol(17 $\beta$ )-di-HFB (fragment ions $m / e 427$ and 644 have respectively a peak abundance of 7769 and 7303 area units) and (2) $5 \alpha$-androstande- $3 \beta, 17 \beta$-diole-di-HFB out of a selected ion monitoring (SIM) analysis of these ions under $\mathrm{NCI} / \mathrm{CH}_{4}$ conditions during 7 to $12 \mathrm{~min}$. 


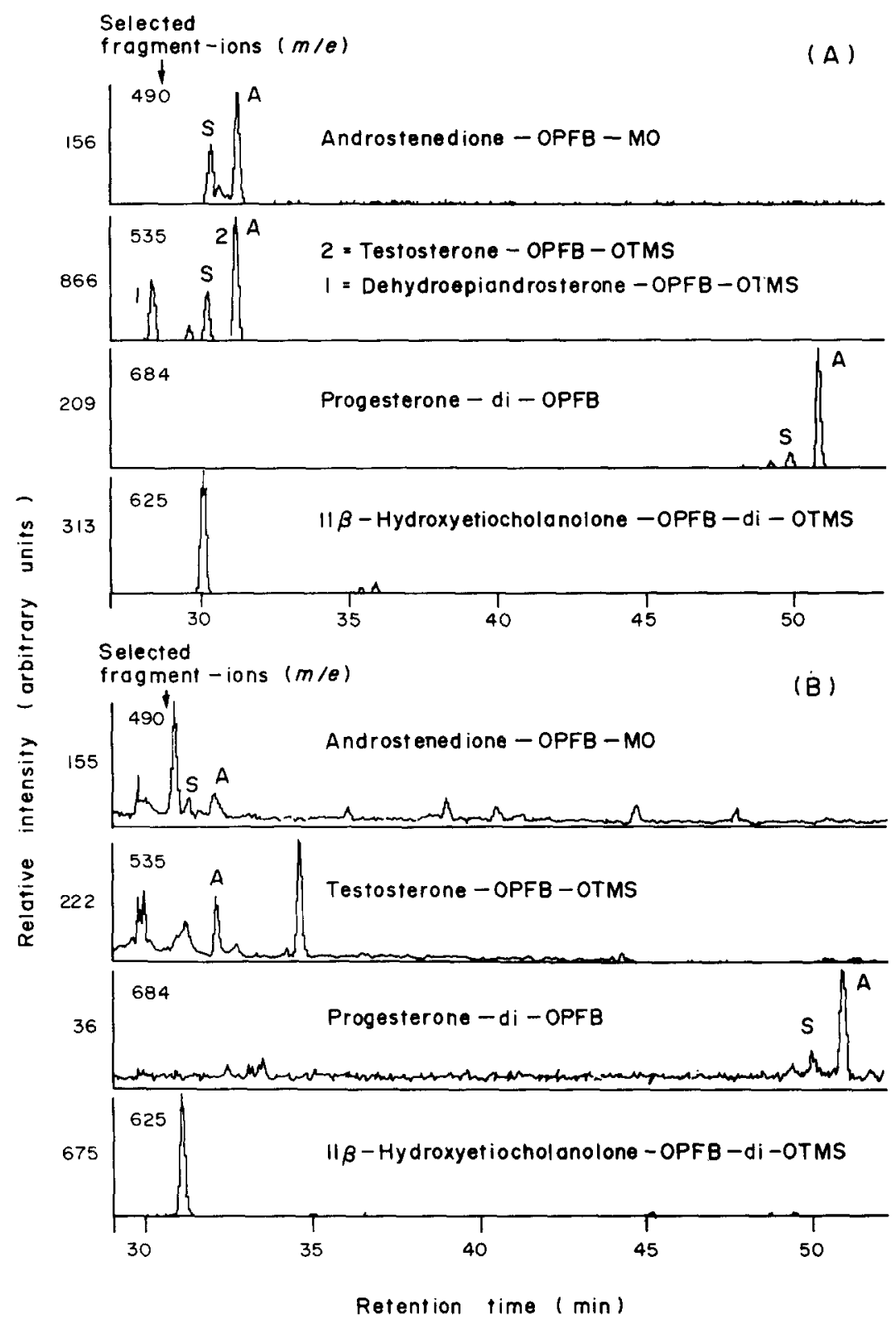

Fig. 4. A reconstruction of the mass fragmentograms of the (M-HF) ions after OPFB-MOOTMS-derivatization. (A) Of standard androstenedione-OPFB-MO ( $m / e$ of 490 ); dehydroepiandrosterone-OPFB-OTMS and testosterone-OPFB-OTMS ( $m / e$ of 535); progesterone-di-OPFB ( $m / e$ of 684$)$ and the internal standard $11 \beta$-hydroxyetiocholanolone-OPFB-di-OTMS ( $m / e$ of 625 ) during 27 to $53 \mathrm{~min}$. (B) Of the extract out of haemolymph from larvae of $S$. bullata of androstenedione-OPFB-MO ( $m / e$ of 490$)$; testosterone-OPFB-OTMS ( $m / e$ of 535 ); progesterone-di-OPFB ( $m / e$ of 684$)$ and the added internal standard $11 \beta$-hydroxyetiocholanolone-OPFB-di-OTMS $(m / e$ of 625$)$ during 29 to 52 min out of a selected ion monitoring (SIM) analysis of these ions under $\mathrm{NCI} / \mathrm{CH}_{4}$ conditions. The syn (S) and anti

(A) isomers of the derivatives are indicated.

standard mixture without cholesterol. The same phenomenon could be demonstrated by adding cholesterol to a standard mixture of steroid derivatives. After cholesterol-HFB injection the degraded product causes a retarding effect on the steroids which are eluted during a 10 -min period after the retention time of cholesterol-HFB. Therefore the same restriction has to be made for the other SIM data of haemolymph extract in which the OPFB-MO-OTMS derivatives have approx. a 1 min longer (Figs $4 \mathrm{~B}$ and 5B) and the OPFB-HFB derivatives an approx. 2 min longer (Fig. 6B) retention time as have the corresponding mixtures of standards without cholesterol (Figs 4A, 5A and 6A). 


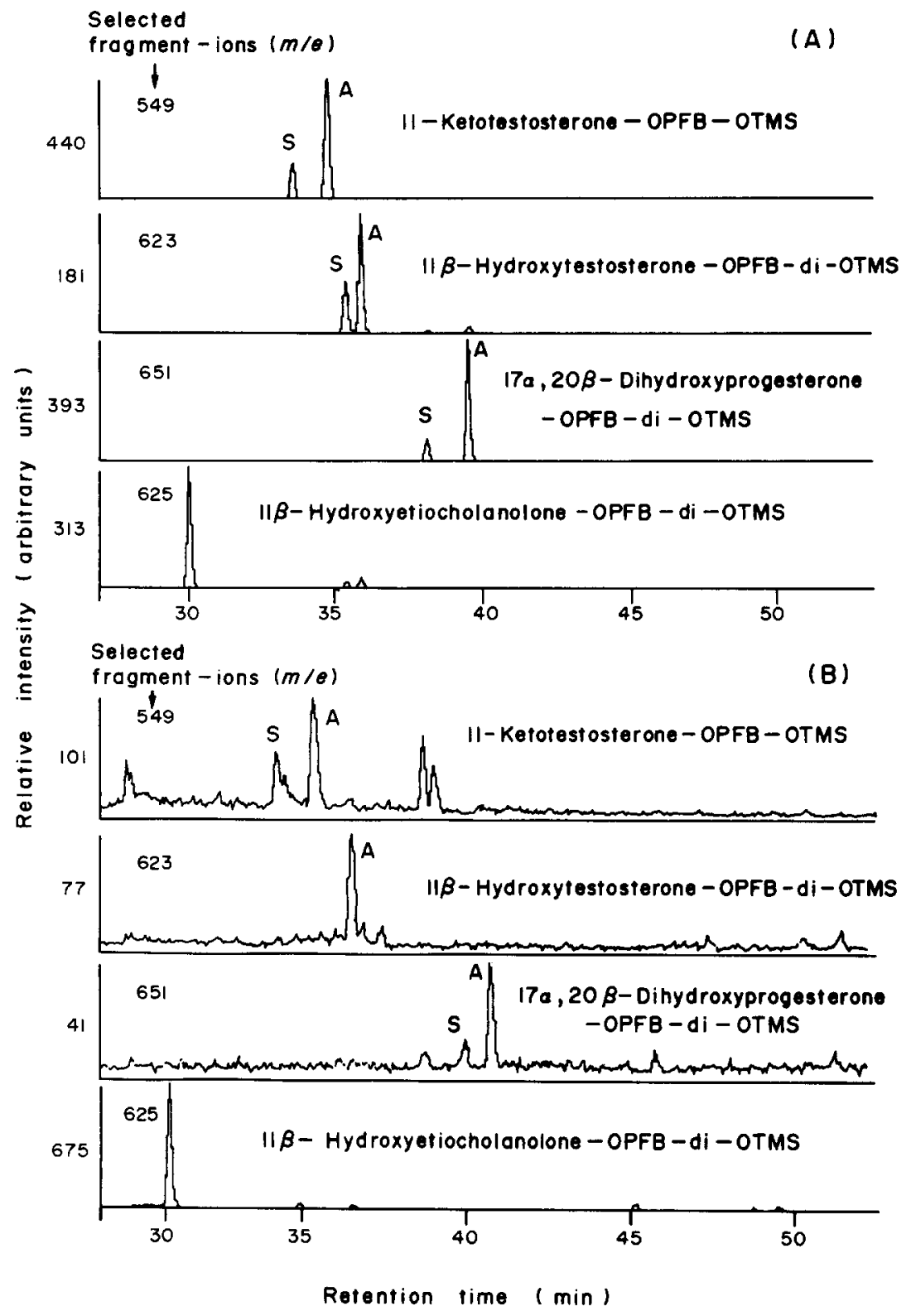

Fig. 5. A reconstruction of the mass fragmentograms of the (M-HF) ions after OPFB-MOOTMS-derivatization. (A) Standard 11-ketotestosterone-OPFB OTMS ( $m / e$ of 549 ); $11 \beta$-hydroxytestosterone-OPFB-di-OTMS ( $m / e$ of 623 ); $17 \alpha, 20 \beta$-dihydroxyprogesterone-OPFB-di-OTMS $(m / e$ of $651)$ and the internal standard $11 \beta$-hydroxyetiocholanolone-OPFB-di-OTMS ( $m / e$ of 625 ) during 27 to $53 \mathrm{~min}$. (B) The extract out of haemolymph from larvae of $S$. bullata of 11-ketotestosteroneOPFB-OTMS ( $m / e$ of 549 ); $11 \beta$-hydroxytestosterone-OPFB-di-OTMS ( $m / e$ of 623 ); $17 \alpha, 20 \beta$-dihydroxyprogesterone-OPFB-di-OTMS ( $m / e$ of 651$)$ and the internal standard $11 \beta$-hydroxyetiocholanoloneOPFB-di-OTMS ( $m / e$ of 625 ) during 28 to $52 \mathrm{~min}$ out of a selected ion monitoring (SIM) analysis of these ions under $\mathrm{NCI} / \mathrm{CH}_{4}$ conditions. The syn (S) and anti (A) isomers of the derivatives are indicated.

\section{Identification of androstenedione}

After preparing two kinds of derivatives we could monitor the (M-HF)-fragment ion of androstenedione-OPFB-MO ( $m / e$ of 490.2, Fig. 4B) and androstenedione-OPFB ( $m / e$ of 461.3 , Fig. 6B) in the haemolymph extract with SIM analysis at a retention time of respectively 32.00 and $31.35 \mathrm{~min}$ for the anti-isomers (Figs 4B and 6B), compared to a retention time of their standards of respectively 31.05 and $30.30 \mathrm{~min}$ (Figs 4A and 6A).

\section{Identification of 11-ketotestosterone}

With SIM analysis we found the (M-HF) fragment ion of 11-ketotestosterone-OPFB-OTMS $(\mathrm{m} / \mathrm{e}$ of 549.2 , Fig. 5B) and of 11-ketotestosteroneOPFB-HFB ( $m / e$ of 673.3 , Fig. 6B) at a retention 


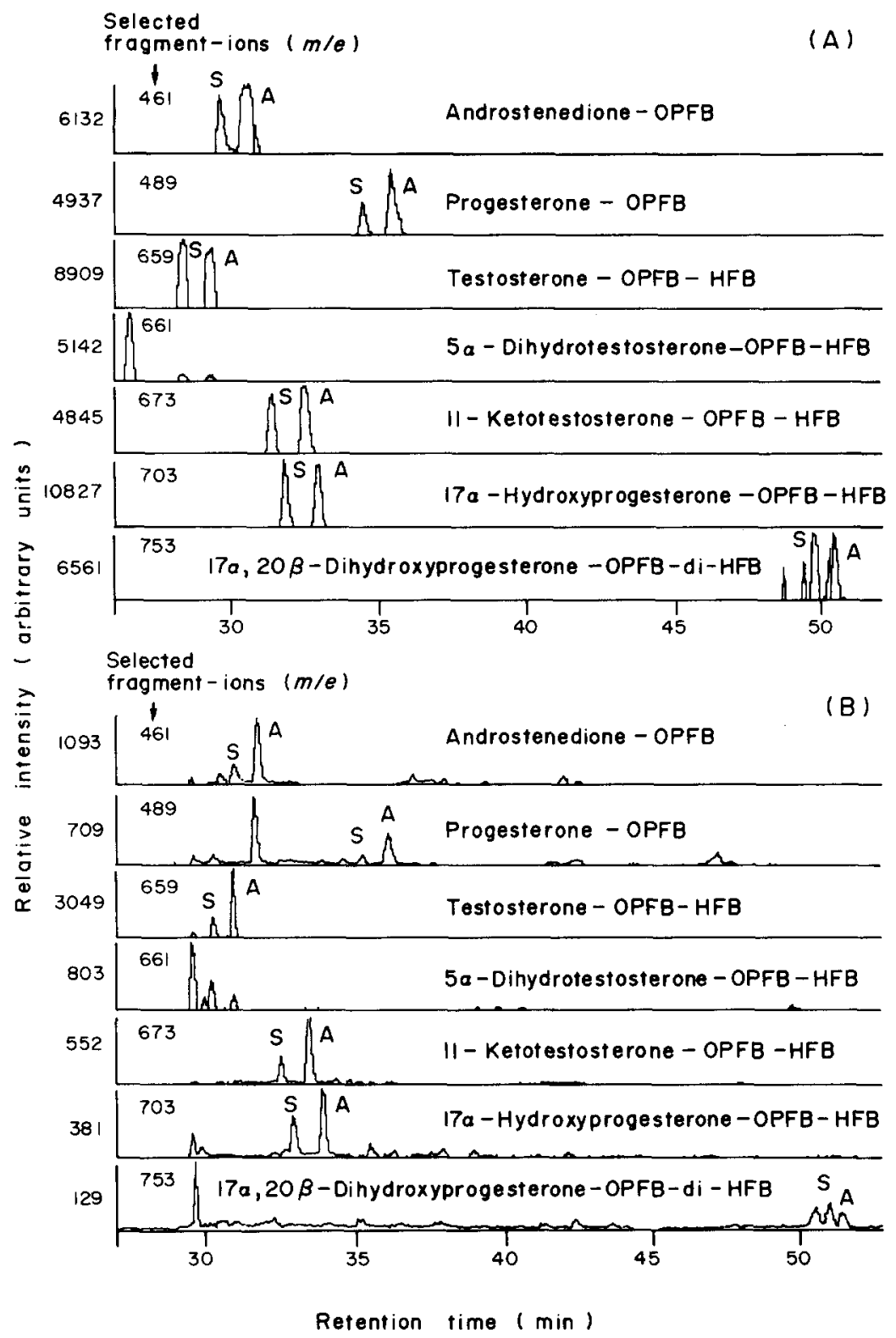

Fig. 6. A reconstruction of the mass fragmentograms of the indicated characteristic ions after OPFB-HFB-derivatization. (A) Standard androstenedione-OPFB $(m / e$ of 461$)$; progesterone-OPFB ( $m / e$ of 489); testosterone-OPFB-HFB ( $m / e$ of $659 ; 5 \alpha$-dihydrotestosterone-OPFB-HFB $(m / e$ of 661$)$; 11-ketotestosterone-OPFB-HFB ( $m / e$ of 673$) ; 17 \alpha$-hydroxyprogesterone-OPFB-HFB $(m / e$ of 703$)$ and $17 \alpha, 20 \beta$-dihydroxyprogesterone-OPFB-di-HFB ( $\mathrm{m} / \mathrm{e}$ of 753 ) during 26 to $52 \mathrm{~min}$. (B) The extract out of haemolymph from larvae of $S$. bullata of androstenedione-OPFB ( $m / e$ of 461$)$; progesterone-OPFB $(m / e$ of 489); testosterone-OPFB-HFB ( $m / e$ of 659$)$; $5 \alpha$-dihydrotestereone-OPFB-HFB $(m / e$ of 661$)$; 11-ketotestosterone-OPFB-HFB ( $m / e$ of 673$) ; 17 \alpha, 20 \beta$-dihydroxyprogestereone-OPFB-di-HFB ( $m / e$ of 753 ); $17 \alpha$-hydroxyprogesterone-OPFB-HFB ( $m / e$ of 703 ) during 27 to $53 \mathrm{~min}$ out of a selected ion monitoring (SIM) analysis of these ions under $\mathrm{NCI} / \mathrm{CH}_{4}$ conditions. The syn (S) and anti (A) isomers of the derivatives are indicated.

time of respectively 35.30 and $33.30 \mathrm{~min}$ for the anti-isomers (Figs 5B and 6B), compared with a retention time of their standards of respectively 34.40 and $32.20 \mathrm{~min}$ (Figs $5 \mathrm{~A}$ and $6 \mathrm{~A}$ ).

\section{Identification of $11 \beta$-hydraxytestosterone}

The characteristic (M-HF) fragment ion of $11 \beta$-hydroxytestosterone-OPFB-di-OTMS ( $m / e$ of
623.2, Fig. 5B) was monitored with SIM analysis of a haemolymph extract at a retention time of $36.60 \mathrm{~min}$ for the anti-isomer (Fig. 5B), compared to a retention time of $36.00 \mathrm{~min}$ for the standard (Fig. 5A).

\section{Identification of $17 \alpha$-hydroxyprogesterone}

After OPFB-HFB derivatization of a haemolymph 
extract the SIM analysis detected the (M-HF) fragment ion of $17 \alpha$-hydroxyprogesterone-OPFB-HFB ( $m / e$ of 703.3, Fig. 6B) at retention time $33.95 \mathrm{~min}$ for the anti-oxime isomer, compared to $33.00 \mathrm{~min}$ for the standard (Fig. 6A).

\section{Identification of $17 \alpha, 20 \beta$-dihydroxyprogesterone}

With the SIM analysis of a derivatized haemolymph extract we detected the (M-HF) fragment ion of $17 \alpha, 20 \beta$-dihydroxyprogesterone-OPFBdi-OTMS ( $m / e$ of 651.2 , Fig. 5B) and $17 \alpha, 20 \beta$-dihydroxyprogesterone-OPFB-di-HFB ( $m / e$ of 753.4 ; $(\mathrm{M}+1)-\left(\mathrm{C}_{6} \mathrm{~F}_{5}\right)$-ion, Fig. $\left.6 \mathrm{~B}\right)$ at retention time of respectively 40.85 and $51.40 \mathrm{~min}$ (Figs $5 \mathrm{~B}$ and $6 \mathrm{~B}$ ), compared to a retention time of their standards of respectively 39.60 and $50.30 \mathrm{~min}$ (Figs $5 \mathrm{~A}$ and $6 \mathrm{~A}$ ).

\section{DISCUSSION}

Our results clearly show that ecdysteroids are not the only steroids present in the haemolymph of larvae of $S$. bullata. There are several reasons why it has taken so long for the non-ecdysteroid steroids we describe in this paper to be identified. Firstly, there is a deeply rooted conviction that the endocrine system of invertebrates is totally different from that of vertebrates. The logical consequence of this is that it does not make sense to search for vertebrate-type hormones in invertebrates and vice versa. Secondly, the concentrations of non-edysteroid steroids which have now been found in invertebrates are very low. The high concentration of ecdysteroids during metamorphosis, which is of the order of at least $200 \mathrm{ng} / \mathrm{g}$ fresh weight, caused many investigators to think that in insects a similar concentration of steroid hormones would be necessary before they would have any physiological significance. It has taken us quite a lot of effort to show that even for ecdysterone $1 \mathrm{ng} / \mathrm{g}$ titres are physiologically active (Huybrechts and De Loof, 1981, 1982). Nanogramme/g titres are quite normal in vertebrates.

The discovery, in our laboratory, that in Diptera ecdysterone is the hormone which is able to induce vitellogenin synthesis in males, has led us to suggest that insects do have sex hormones. Diptera, at least, seem to use their moulting hormone as the equivalent of estrogens in vertebrates. This hypothesis is quite well supported in Diptera (Huybrechts and De Loof, 1977, 1981, 1982; De Clerck and De Loof, 1983; Stoppie et al., 1981; De Loof, 1982; Postlethwaith and Handler, 1979).

The presence of a male sex hormone is more questionable. Although Naisse (1966a,b,c and 1969) gave evidence for the existence of such a hormone in the firefly Lampyris noctiluca, further progress has not been reported. If insects have a male sex hormone, there is a good chance that it would be a steroid; either an ecdysteroid or a vertebrate-type steroid (De Loof, 1982). Metabolism studies of $\left[{ }^{3} \mathrm{H}\right]$ ecdysone in adult $S$. bullata did not give any indication for the existence of a male specific ecdysteroid (Briers et al., 1983). We therefore looked for testosterone and its precursors and metabolites, taking into account that titres of $\mathrm{ng} / \mathrm{ml}$ haemolymph might be the concentration at which they are of physiological importance.
At present, it would be premature to conclude that testosterone or a derivative functions as a male sex hormone in insects. As long as there is no conclusive bioassay for the screening of androgenic hormones in insects, definitive answers as to their role are not possible.

However, the discovery that progesterone and testosterone are present in the haemolymph of highly evolved invertebrates is very interesting from the point of view of evolutionary theory. According to Sandor and Mehdi (1979) steroids are very ancient and conservative molecules, probably going back to the origin of life. As progesterone and testosterone are present in the highly evolved invertebrates, it seems resonable to assume that they also occur in all lower Phyla. The absence of estrogens in Diptera is not fully unexpected. Indeed, we discovered that Diptera, and in our opinion all insects, seem to use their moulting hormone also as a female sex hormone. Injection of estradiol in male or female $S$. bullata never induced or stimulated vitellogenin synthesis (Huybrechts and De Loof, 1981). The absence of estrogens in $S$. bullata in the presence of androstenedione and testosterone suggests the absence of the aromatizing enzyme. This is another argument in favour of the hypothesis that evolution can occur by gaining new genetic information as well as by loosing existing information. Vertebrates seem to have lost the capacity to transform cholesterol into ecdysteroids and insects seem to have lost not only the capacity to transform farnesylpyrophosphate into cholesterol (the origin of juvenile hormone, De Loof, 1982) but also the capacity to transform testosterone into estrogens.

The list of steroids identified already suggests the major steps of the biosynthetic pathway of testosterone in $S$. bullata. Starting from progesterone, we find $17 \alpha$-hydroxyprogesterone, androstenedione, testosterone and even further metabolites like $5 \alpha$-dihydrotestosterone, 11-ketotestosterone and $11 \beta$-hydroxytestosterone. The other metabolites androstenediole, $5 \alpha$-androstane- $3 \beta, 17 \beta$-diole and $5 \beta$-androstane- $3 \alpha, 17 \beta$-diole suggest an analogous degradation pathway to that in vertebrates. In vivo metabolism studies with $S$. bullata larvae using tritiated precursors of different steroids have almost been completed and the data obtained so far indicate the presence of all the enzymes necessary for the biosynthetic pathway suggested above.

Recent results (to be published elsewhere) of our further investigations in haemolymph of larvae of the Colorado beetle Leptinotarsa decemlineata revealed practically the same results as presented here. This decreases the possibility that these steroids are derived from the dietary source.

To overcome the problem of the retarding effect on the retention time of the steroid derivatives out of biological samples, Gaskell and Brooks (1983) used immunoadsorption extraction for testosterone and estradiol. This excellent technique causes a low background and may filter off cholesterol like substances. Since we are looking for as many steroids as possible in the biological sample we could not use this technique, due to the lack of so many different antibodies for each steroid. The use of isobutane as reagent gas may be favourable for the detection of these steroid 
derivatives, as was used for the detection of estradiol-di-HFB in biological samples by Gaskell and Brooks (1983). However we used methane as reagent gas in order to get more fragmentation of the derivatives which is more useful for identification purposes.

The major result of our study is that the endocrine system of insects is probably much more complicated than generally assumed and that its basic principles are not fundamentally different from those in vertebrates or other Phyla (De Loof, 1982). In our opinion there are still many hormones to be discovered, and it is the balance of hormones rather than any one individual hormone which is of crucial importance for the regulation of physiological processes (De Loof, 1982). How a balance of hormones can regulate a physiological process cannot be explained by the Jensen hypothesis but the recently introduced concept that most cells are miniature electrophoresis chambers and that epigenetic control of gene expression might be an electrical phenomenon (De Loof et al., 1982) could lead to new insight in endocrinology.

Acknowledgements-We thank the I.W.O.N.L. of Belgium for providing a Research Scholarship to D. De Clerck. We also thank Mrs Puttemans for the drawings, Mr Evans for critical evaluation of the text and the Applied Mass spectrometrical and toxicological Laboratory (AMTOL B.V.), Kleverparkweg 13rd, $2023 \mathrm{CA}$ Haarlem, The Netherlands for the NCI/GC-MS analyses.

\section{REFERENCES}

Axelson M. (1978) Exchange of oxime functions: A useful reaction in GC-MS analysis of steroids. Analyt. Biochem. 86, 133-141.

Briers T., De Clerck D., Van Beek E. and De Loof A. (1983) Metabolism of injected $\left({ }^{3} \mathrm{H}\right)$-ecdysone in male Sarcophaga bullata (Diptera). Gen. comp. Endocr. In press.

Burlingame A. L., Dell A. and Russell D. H. (1982) Mass Spectrometry; Reviews/April 1982. Analyt Chem. 54, 363R-409R.

De Clerck D., Eechaute W., Leusen I., Diederik H. and De Loof A. (1983) Identification of testosterone and progesterone in a haemolymph of larvae of the fleshfly Sarcophaga bullata. Gen. comp. Endocr. In press.

De Clerck D. and De Loof A. (1983) Effect of dietary ecdysterone on protein ingestion and copulatory behaviour of Sarcophaga bullata. Physiol. ent. 8, 243-249.

De Loof A. (1982) New concepts in endocrine control of vitellogenesis and in functioning of the ovary in insects. In exogenous and Endogenous Influences on Metabolic and Neurol Control (Edited by Addink A. D. F. and Spronk N.), pp. 165-177. Pergamon Press, Oxford.

De Loof A., Briers T., Huybrechts R., Ollevier F., Peferoen M., Stoppie P. and Stynen D. (1982) Hormones, ion pumps and control of gene expression. The cell as a miniature electrophoresis chamber? Annls Soc. r. zool. Belg. 112, 3-22.

Diederik H. and Lambert J. G. D. (1982) Steroids in plasma of the female rainbow trout before and after ovulation by NCI-GC/MS. In Proc. Intern. Symp. Reprod. Physiol. Fish (Edited by Richter C. J. J. and Goos H. J. Th.), pp. 107-108. Pudoc, Wageningen, The Netherlands.

Francis A. J., Morgan E. D. and Poole C. F. (1978) Flophemesyl derivatives of alcohols, phenols, amines and carboxylic acids and their use in gas chromatography with electron-capture detection. J. Chromat. 161, 111-117.

Gaskell S. J. and Brooks P. W. (1983) High sensitivity analyses of steroids using gas chromatography-negative chemical ionisation mass spectrometry. Int. J. Mass Spectrom. Ion. Phys. 48, 241-244.

Gleispach H., Wurz E. and Mayek B. (1981) Measurements of plasma steroids in the femtomole range using gas chromatography-mass spectrometry. In Analytical Chemistry Symposia Series - volume 10 "Advances in Steroid Analysis", Proc. Symp. on the Analysis of Steroids (Edited by Görög), pp. 307-314. Elsevier, Amsterdam.

Horning M. G., Moss A. M. and Horning E. C. (1968) Formation and gas-liquid chromatographic behavior of isometric steroid ketone methoxime derivatives. Analyt. Biochem. 22, 284-294.

Hunt D. F. and Crow F. W. (1978) Electron capture negative ion chemical ionization mass spectrometry. Analyt. Chem. 50, 1781-1784.

Huybrechts R. and De Loof A. (1977) Induction of vitellogenin synthesis in male Sarcophaga bullata by ecdysterone. J. Insect Physiol. 23, 1359-1362.

Huybrechts R. and De Loof A. (1981) Effect of ecdysterone on vitellogenin concentration in haemolymph of male and female Sarcophaga bullata. Int. J. Invertebr. Reprod. 3, $157-168$.

Huybrechts R. and De Loof A. (1982) Similarities in vitellogenin and control of vitellogenin synthesis within the genera Sarcophaga. Calliphora. Phormia and Lucilia (Diptera). Comp. Biochem. Physiol. 72B, 339-344.

Leunissen W. J. J. and Thyssen J. H. H. (1978) Quantitative analysis of steroid profiles from urine by capillary gas chromatography. J. Chromat. 146, 365-380.

Markey S. P., Lewy A. J. and Colburn R. W. (1978) Studies in biogenic amine metabolism by mass spectrometry. In Quantitative Mass Spectrometry in Life Sciences 11 (Edited by de Leenheer A. P., Rocucci R. R. and van Peteghem), pp. 17-37. Elsevier, Amsterdam.

McLafferty F. W. (1980) Interpretation of Mass Spectra. 3rd edn. Table 2.2. Isotopic Contributions for Carbon and Hydrogens. University Science Books, Mill Valley, California.

Naisse J. (1966a) Contrôle endocrinien de la différenciation sexuelle chez l'insecte Lampyris noctiluca. I. Rôle androgène des testicules. Archs Biol. 77, 139-201.

Naisse J. (1966b) Contrôle endocrinien de la différenciation sexuelle chex Lampyris noctiluca. II. Phénomènes neurosécrétoires et endocrines au cours du développement postembryonnaire chez le mâle et la femelle. Gen. comp. Endocr. 7, 85-104.

Naisse J. (1966c) Contrôle endocrinien de la différenciation sexuelle chez Lampyris noctiluca. III. Influence des hormones de la pars intercerebralis. Gen. comp. Endocr. 7, $105-110$.

Naisse J. (1969) Rôles des neurohormones dans la différenciation sexuelle de Lampyris noctiluca. J. Insect Physiol. 15, 877-892.

Poole C. F. and Zlatkis A. (1980) Cyclic derivatives for the selective chromatographic analysis of bifunctional compounds. J. Chromat. 184, 99-183.

Postlethwaith J. H. and Handler A. M. (1979) The role of juvenille hormone and 20-hydroxyecdysone during vitellogenesis in isolated abdomens of Drosophila melangoster. J. Insect Physiol. 25, 455-460.

Sandor T. and Mehdi A. E. (1979) Steroids and evolution. In Hormones and Evolution (Edited by Barrington J. E. W.), pp. 1-72. Academic Press, New York.

Stoppie P., Briers T., Huybrechts R. and De Loof A. (1981) Moulting hormone, juvenile hormone and the ultrastructure of the fat body of adult Sarcophaga bullata. Cell Tiss. Res. 221, 233-244. 